\title{
Ankilozan Spondilitli Hastaların Uyku Kalitesinin Çeşitli Değişkenler Açısından Değerlendirilmesi
}

\section{Evaluation of Sleep Quality of Patients with Ankylosing Spondylitis in Terms of Various Variables}

\author{
(1DSibel Şentürk', @Derya Bıçak Ayık² \\ 'Burdur Mehmet Akif Ersoy Üniversitesi, Bucak Sağlık Yüksekokulu, Hemşirelik Bölümü, Burdur, Türkiye \\ ${ }^{2}$ Siirt Üniversitesi, Sağlık Bilimleri Fakültesi, Ebelik Bölümü, Siirt, Türkiye \\ Copyright@Author(s) - Available online at www.dergipark.org.tr/tr/pub/medr \\ Content of this journal is licensed under a Creative Commons Attribution-NonCommercial 4.0 International License.
}

\section{Öz}

Amaç: Bu çalışma, ankilozan spondilitli hastaların uyku kalitesini değerlendirmek ve uyku kalitesini etkileyebilecek faktörleri belirlemek amacıyla yapıldı.

Materyal ve Metot: Tanımlayıcı ve kesitsel tipteki bu çalışma, Aralık 2018-Mayıs 2019 tarihleri arasında Romatoloji polikliniğinde takip edilen, hekim tarafından Modifıye New York Kriterlerine göre ankilozan spondilit tanısı almış, en az 1 yıldır ankilozan spondilit rahatsızlığı olan 70 hasta ve sağıklı 70 kontrol grubu ile tamamlandı. Veriler, araştırmacılar tarafından oluşturulan "Hasta Bilgi Formu" ve "Pittsburgh Uyku Kalitesi Ölçeği" ile elde edildi. Verilerin değerlendirilmesinde yüzdelik dağılımlar, ki-kare testi, Student $t$ testi ve One-way Anova testi kullanıldı.

Bulgular. Ankilozan spondilitli hastaların \%85,8'inin uyku kalitesinin kötü ve Pittsburgh Uyku Kalitesi Ölçeği toplam puanının 7,72 $\pm 4,38$ olduğu, kontrol grubunun ise sadece \%17,1'inin uyku kalitesinin kötü olduğu ve Pittsburgh Uyku Kalitesi Ölçeği toplam puanının $3,91 \pm 3,57$ olduğu belirlendi. Araştırmaya dahil edilen ankilozan spondilitli hastaların yaş, egzersiz yapma, eğitim durumu ve hastalık yılı değişkenleri ile uyku kalitesi bileşenleri arasında ise istatistiksel olarak anlamlı bir ilişki saptandı $(p<0,05)$.

Sonuç: Ankilozan spondilitli hastaların uyku kalitesinin sağlıklı kişilere göre kötü olduğu belirlendi. Sağlık personeli tarafından, ankilozan spondilitli hastalarda uyku problemlerine neden olan durumların tespit edilmesi ve bu durumlara ilişkin gerekli girişimlerin yapılması önerilmektedir.

Anahtar Kelimeler. Ankilozan spondilit; uyku problemi; uyku kalitesi

\section{Abstract}

Aim: This study was conducted to evaluate the sleep quality of patients with ankylosing spondylitis and to determine the factors that may affect sleep quality.

Material and Method: This descriptive and cross-sectional study was conducted between December 2018 and May 2019 . It was completed with 70 patients followed in the rheumatology outpatient clinic, diagnosed with ankylosing spondylitis according to the Modified New York Criteria by a physician, and who had ankylosing spondylitis for at least 1 year and 70 healthy controls. The data were obtained using the "Patient Information Form" created by the researchers and "Pittsburgh Sleep Quality Scale" created by the researchers. The analysis of the data was done by descriptive statistics, chi-square test, Student t test and One-way Anova test. Results: It was determined that $85.8 \%$ of the patients with ankylosing spondylitis had poor sleep quality and the Pittsburgh Sleep Quality Scale total score was $7.72 \pm 4.38$. It was determined that only $17.1 \%$ of the control group had poor sleep quality and the total score of Pittsburgh Sleep Quality Scale was $3.91 \pm 3.57$. A statistically significant relationship was found between age , exercise, educational status and years of illness and sleep quality components of the patients with ankylosing spondylitis included in the study $(p<0.05)$.

Conclusions: It was determined that the sleep quality of patients with ankylosing spondylitis was worse than healthy people. It is recommended by the healthcare personnel to determine the conditions that cause sleep problems in patients with ankylosing spondylitis and to take necessary actions regarding these situations.

Keywords: Ankylosing spondylitis; sleep problem; sleep quality 


\section{GíRiş}

Ankilozan spondilit (AS), omurgayı, sakroiliak ve periferik eklemleri etkileyen, çeşitli derecelerde yapısal ve fonksiyonel bozukluklara, omurganın hareketliliğinin azalmasına ve bel ağrısına neden olan kronik, sistemik ve inflamatuar bir hastalıktır (1-3). AS'nin kesin etiyolojisi belirsizliğini korumakla birlikte HLA-B27 antijeni, genetik ve çevresel faktörlerle ilişkili olduğu bilinmekte ve hastalığın prevalansı yaklaşık olarak \%0,4 ile $\% 1,4$ aralığında değişmektedir (4-8).

Erken evrede hastalık sakroiliak eklemleri etkilemekte ancak hastalığın ileri evresinde aksiyal iskeleti de etkileyebilmektedir (9). İnflamatuar mekanizmaya bağlı olarak, hastalığın farklı evrelerinde ilerleyici sınırlı spinal hareketlilik ve geri dönüşü olmayan yapısal değişiklikler gibi hastalığa bağlı çeşitli bozukluklar ortaya çıkabilmektedir (10). Uykudan uyandıran bel ağrısı ve tutukluk, AS'nin karakteristik özelliğidir. Bunun yanı sıra yorgunluk, fonksiyonel bozukluk, hareket sınırlılığı, anksiyete, depresyon, düşük yaşam kalitesi ve uyku bozukluğu gibi birçok sorun yaşanabilmektedir (4,8-13).

AS hastalarında uyku bozukluklarının normal popülasyona göre daha sık olduğu ve bu hastalarda uyku bozukluğu prevalansının \%35 ile \%90 arasında olduğu bildirilmektedir $(1,6,9,10,13,14)$. Hastalar genellikle düşük uyku kalitesi, uykuya dalamamaya bağlı uyuklama hali, uyanmada zorluk ve obstrüktif uyku apnesi sendromundan şikayet etmektedirler (11-13). AS hastalarında uyku bozukluğunun birçok nedeni vardır. Tipik bir AS semptomu olan gece ağrısı, uyku kalitesini olumsuz yönde etkileyen en önemli faktörlerinden biri olarak kabul edilmektedir (15). Aksiyal omurgadaki ağrı ve sertlik fonksiyonel yeteneği ve yaşam kalitesini olumsuz yönde etkilemekte olup AS hastalarında kötü uyku kalitesi ile ilişkilendirilmektedir (10). Uyku bozukluğunun AS hastalarında, psikolojik stres, dikkat eksikliği, öğrenme güçlüğü, işlevsellikte azalma, şiddetli yorgunluk gibi olumsuz fiziksel, psikolojik ve sosyal etkilere, hastalık semptomlarının şiddetlenmesine ve genel iyilik halinin bozulmasına neden olduğu ifade edilmektedir $(1,8,9,13)$. Bu nedenle AS hastalarında uyku kalitelerinin iyileştirilmesi için uyku ile ilgili faktörlerin araştırılması gerekmektedir. Bu sonuçlardan hareketle çalışmamız, AS'li hastaların uyku kalitesini değerlendirmek ve uyku kalitesini etkileyebilecek faktörleri belirlemek amacıyla yapılmıştır.

\section{MATERYAL VE METOT}

Araştırma Tipi: Bu araştırma, AS hastalarının uyku kalitesini değerlendirmek ve uyku kalitesini etkileyebilecek faktörleri belirlemek amacıyla tanımlayıcı ve kesitsel olarak yapıldı.

Araştırmanın Evren ve Örneklemi: Araştırmada örneklem seçimine gidilmemiş evrenin tamamına ulaşılması hedeflenmiştir. Araştırmanın kapsamını Türkiye'nin güneyinde yer alan bir Eğitim ve Araştırma Hastanesi'nde Aralık 2018- Mayıs 2019 tarihleri arasında (a) 18 yaş ve üzerinde olan, (b) iletişim ve algılama problemi bulunmayan, (c) çalışmaya katılmayı kabul eden ve (d) çalışmanın yapıldığı tarihlerde Romatoloji polikliniğine muayeneye gelen Modifiye New York Kriterlerine göre AS tanısı konmuş 70 hasta oluşturdu. Kontrol grubunu ise çalışmanın yapııdığı hastanenin aile hekimliği polikliniğine rutin kontrol için gelen, AS hasta grubuyla yaş ve cinsiyet bakımından uyumlu 70 sağlıklı gönüllüler oluşturdu. AS hastaları için uygulanan dışlanma kriterleri kontrol grubu içinde uygulandı.

Verilerin Toplanması: Veriler, araştırmacıların literatür incelemesi sonucu oluşturduğu 'Hasta Bilgi Formu' $(6,10,11,14)$ ve Pittsburgh Uyku Kalitesi İndeksi (PUKi) ile toplandı. Uygulama öncesi 5 AS'li bireye anket formu uygulandı ve anketin son kontrolleri yapıldı. Anketler, yüz yüze görüşme tekniği kullanılarak toplandı. Araştırmaya katılan bireylere çalışma hakkında bilgilendirme yapıldıktan sonra yazılı ve sözlü onamları alındı. Anket formlarının doldurulması 15-20dk içerisinde tamamlandı.

\section{Veri Toplama Araçları}

Hasta Bilgi Formu: Literatür taranarak oluşturulan $(6,10,11,14)$ hasta bilgi formu; yaş, cinsiyet, medeni durum, eğitim durumu, meslek, düzenli egzersiz yapma durumu, sigara içme, alkol kullanma, hastalık süresi, eşlik eden hastalıklar, ilaçlarını düzenli kullanma, kontrollere düzenli gelme ve destek kişilerin varlığı gibi toplam 13 sorudan oluşmaktaydı.

Pittsburgh Uyku Kalitesi İndeksi (PUKi): Pittsburgh Uyku Kalitesi İndeksi (PUKI), Buysse ve ark. tarafından 1989 yılında geliştirilmiştir (16). Türkçe geçerlilik ve güvenilirlik çalışması ise Ağargün ve ark. tarafından 1996 yılında yapılmıştır (17). PUKi, son bir ay içerisinde bireylerin uyku kalitesini ve buna bağlı bozuklukların belirlenmesinde kullanılan bir ölçektir. 7 bileşenden oluşan ve her sorunun cevabı 0 ile 3 arasında puanlanan bir ölçektir. Ölçeğin bileşenleri; öznel uyku kalitesi (bileşen 1), uyku latensi (bileşen 2), uyku süresi (bileşen 3), alışılmış uyku etkinliği (bileşen 4), uyku bozukluğu (bileşen 5), uyku ilacı kullanımı (bileşen 6) ve gündüz işlev bozukluğu (bileşen 7) dur.

PUKI 24 maddeden oluşmasına karşın, 19 madde üzerinden hesaplanmaktadır. Toplam PUKI puanı yedi bileşenin toplamı ile elde edilmekte olup 0 ile21 arasında bir değer almaktadır. Toplam PUKi puanının 0 ile 4 puan aralığında bulunması uyku kalitesinin iyi, 5 ile 21 puan aralığında bulunması ise uyku kalitesinin kötü olduğu şeklinde yorumlanmaktadır. Ölçeğin Cronbach Alpa değeri 0,80'dir. Bu çalışmada ise Cronbach Alpa değeri 0,87 idi.

Verilerin Analizi: Veriler, SPSS 21.0 (Statistical Package for Social Sciences, IBM Inc., Chicago, IL, USA) paket programı ile değerlendirildi. Shapiro-Wilks testi ile verilerin normal dağılıma uygunluğu belirlendi. Tüm değişkenler için tanımlayıcı istatistikler oluşturuldu.

Kategorik değişkenler ki-kare testi kullanılarak karşılaştırıldı. Ankilozan spondilitli hastaların uyku kalitesini etkileyen değişkenler için Student-t ve Oneway Anova testi kullanıldı. Tüm testler için $p<0,05$ değeri anlamlılık düzeyi olarak kabul edildi. 
Araştırmanın Etik Yönü: Çalışma, Helsinki Bildirgesi'ndeki ilkelere riayet edilerek yapıldı ve çalışmaya katılan tüm bireylere uygulamanın gönüllülük ilkesine dayandığı ifade edilerek onamları alındı. Çalışma için Burdur Mehmet Akif Ersoy Üniversitesi Girişimsel Olmayan Klinik Araştırmalar Etik Kurulu'ndan etik kurul izni (Karar No: GO 2018/37) ve çalışmanın yürütüldüğü kurumun Romatoloji $A D$ başkanından da izin alındı.

\section{BULGULAR}

Tablo 1 incelendiğinde, araştırma kapsamına alınan AS'li hastaların \% 60,0'ı erkek, \% 68,5'i 44 yaş ve altında, \% 57, 1'i evli, \% 60,0'ı ilköğretim ve altı eğitime sahip, \% 37,2'si işçi, \% 51,4'ü egzersiz yapmakta ve \% 42,9'unun sigara içtiği belirlendi. Araştırma kapsamındaki kontrol grubunun ise \%
51,4 'ü erkek, 44 yaş ve altı, ilköğretim ve altı eğitime sahip, $\%$ 71,4'ü evli, \% 45,8'i memur, \% 25,8'i egzersiz yapmakta ve \% 28,6 'sının sigara içtiği belirlendi. AS'li hasta ve kontrol grubu arasında sosyo-demografik değişkenler açısından istatistiksel olarak anlamlı bir farklılık saptanmadı ( $p$ > 0.05).

Tablo 2 incelendiğinde, araştırma kapsamına alınan AS'li hastaların \% 65,7'si 1 - 5 yıldır bu hastalığa sahip olduğunu, $\%$ 54,2'si AS dışında ek bir hastalığının bulunduğunu ve bunu \% 42,0 ile Üveit, \% 21,0 ile HT, DM, Gastrit ve ülser, $\% 16,0$ ile astım-bronşit gibi hastalıkların oluşturduğu, $\%$ 85,8'i ilaçlarını düzenli olarak kullandıklarını, \% 77,1'i kontrollere düzenli olarak geldiklerini ve \% 91,4'ü de hastalıkları nedeniyle kendilerine destek olan birilerinin olduğunu belirtti.

Tablo 1. Hasta ve kontrol grubunun sosyo-demografik özelliklerine göre dağlımı

Değişkenler

Cinsiyet

Kadın

Erkek

Yaş

44 yaş ve altı

45 yaş ve üzeri

48

22

Medeni Durum

Evli

Bekar

Eğitim Durumu

Illköğretim ve altı

Ortaöğretim

Yükseköğretim

Meslek

Memur

Ev hanımı

İşçi

Emekli

10

Düzenli Egzersiz

Yapma

Evet

Hayır

Sigara İçme

İçen

İçmeyen

40

Toplam

70

\section{Hasta}

$\%$

40,0

60,0

68,5

31,5

57,1

42,9

60,0

22,9

17,1

17,1

31,5

37,2

14,2

51,4

48,6

42,9

57,1

100,0
Kontrol

Sayı

$\%$

p

48,6

$0,246^{*}$

51,4

51,4

$0,457^{*}$

48,6

71,4

$0,179^{*}$

28,6

51,4

20,0

$0,414^{*}$

28,6

45,8

14,2

$0,186^{*}$

17,1

22,9

16

25,8

$0,324^{*}$

74,2

28,6

$0,066^{*}$

71,4

100,0

*p>0,05, Ki-kare testi 
Araştırmaya katılan AS'li hastaların \% 85,8'inin, kontrol grubunda ise bireylerin \% 17,1 'inin kötü uyku kalitesine sahip olduğu belirlendi. AS'li hastaların kontrol grubuna göre uyku kalitesinin anlamlı derecede düşük olduğu görüldü ( $p<0,01)$ (Tablo 3 ).

Tablo 4'de AS'li hastaların ve kontrol grubunun toplam PUKI puanı ve alt bileşenlerinden aldıkları puanlar verildi. Buna göre AS'li hasta grubunun toplam PUKI puanının $7,72 \pm 4,38$, kontrol grubunun toplam PUKI puanının ise $3,91 \pm 3,57$ olduğu belirlendi.

AS'li hasta ve kontrol grubu uyku kalitesi bileşenleri puan dağılımına bakıldığında; öznel uyku kalitesi, uyku latensi, uyku bozukluğu ve gündüz işlev bozukluğu bileşenleri arasında anlamlı bir fark saptandı $(p<0,05)$. Uyku süresi, alışılmış uyku etkinliği ve uyku ilacı kullanımı yönünden ise anlamlı bir fark saptanmadı $(p>0,05)$.

Çalışma kapsamındaki AS'li hastaların yaş, eğitim durumu, egzersiz yapma, ve hastalık yılı değişkenleri ile uyku kalitesi bileşenleri arasında istatistiksel olarak anlamlı bir ilişki saptanırken $(p<0,05)$; cinsiyet, medeni durum, meslek, eşlik eden hastalıklar, ilaçlarını düzenli kullanma, kontrollere düzenli gelme ve destek kişilerin varlığı değişkenleriyle uyku kalitesi bileşenleri arasında ise istatistiksel olarak anlamlı bir ilişki bulunmadı $(p>0,05)$ (Tablo 5).

\section{Tablo 2. Ankilozan Spondilitli Hastaların Hastalıklarına ilişkin Özelliklerinin Dağıımı}

Değişkenler

Hastalık Süresi ( $n=70)$

$1-5$ yıl

$6-10$ yıl

11 yıl ve üzeri

10

14

Eşlik Eden Hastalık Varlığı

Evet

Hayır

Eşlik Eden Hastalıklar ( $n=38)$

Üveit

$\mathrm{HT}, \mathrm{DM}$ *

Astım, bronşit

İlaçlarını Düzenli Kullanma Durumu

Evet

Hayır

Kontrollere Düzenli Gelme Durumu

Evet

Hayır

Destek Kişilerin Olma Durumu

Evet

Hayır

*HT: Hipertansiyon, DM: Diyabetes mellitus 
Tablo 3. Hasta ve Kontrol Grubunun Uyku Kalitesinin Dağılımı

\begin{tabular}{|c|c|c|c|c|c|}
\hline \multirow[t]{2}{*}{ Değişkenler } & \multicolumn{2}{|c|}{ Hasta Grubu $(n=70)$} & \multicolumn{2}{|c|}{ Kontrol Grubu $(n=70)$} & \multirow[t]{2}{*}{$\mathbf{p}$} \\
\hline & Sayı & $\%$ & Sayı & $\%$ & \\
\hline \multicolumn{6}{|c|}{ Uyku Kalitesi } \\
\hline İyi & 10 & 14,2 & 58 & 82,9 & \\
\hline Kötü & 60 & 85,8 & 12 & 17,1 & $0.000^{*}$ \\
\hline Toplam & 70 & 100,0 & 70 & 100,0 & \\
\hline
\end{tabular}

Tablo 4. Uyku Kalitesi Bileşenlerinin Puan Dağılımı

$\begin{array}{lccc}\text { Uyku Bileşenleri } & \text { Hasta Grubu }(\mathbf{n}=\mathbf{7 0}) & \text { Kontrol Grubu }(\mathbf{n}=\mathbf{7 0}) & \mathbf{p} \\ \text { Öznel Uyku Kalitesi } & 1,80 \pm 0,67 & 0,80 \pm 0,58 & 0,000 * \\ \text { Uyku Latensi } & 1,60 \pm 1,03 & 0,71 \pm 0,78 & 0,000 * \\ \text { Uyku Süresi } & 0,74 \pm 0,78 & 0,68 \pm 0,63 & 0,737 \\ \text { Alışılmış Uyku Etkinliği } & 0,14 \pm 0,42 & 0,20 \pm 0,40 & 0,569 \\ \text { Uyku Bozukluğu } & 1,71 \pm 0,75 & 1,05 \pm 0,41 & 0,000 \text { * } \\ \text { Uyku Ilacı Kullanımı } & 0,02 \pm 0,16 & 0,02 \pm 0,16 & 1,000 \\ \text { Gündüz İşlev Bozukluğu } & 1,71 \pm 0,57 & 0,45 \pm 0,61 & 0,000 * \\ \text { Toplam PUKi } & 7,72 \pm 4,38 & 3,91 \pm 3,57 & \\ \text { *p<0,01, Student t testi } & & & \end{array}$

Tabı 5. Ankilozan Spondilittli Hastaların Bazı Özellikleri İle Uyku Kalitesi Arasındaki Ilişkinin Dağı̆ımı

\begin{tabular}{|c|c|c|c|c|c|c|c|c|}
\hline Değişkenler & $\begin{array}{l}\text { Öznel Uyku } \\
\text { Kalitesi }\end{array}$ & $\begin{array}{l}\text { Uyku } \\
\text { Latensi }\end{array}$ & Uyku Süresi & $\begin{array}{l}\text { Alışılmış } \\
\text { Uyku } \\
\text { Etkinliği }\end{array}$ & $\begin{array}{c}\text { Uyku } \\
\text { Bozukluğu }\end{array}$ & $\begin{array}{l}\text { Uyku İlacı } \\
\text { Kullanımı }\end{array}$ & $\begin{array}{l}\text { Gündüz İşlev } \\
\text { Bozukluğu }\end{array}$ & $\begin{array}{l}\text { Toplam Uyku } \\
\text { Kalitesi }\end{array}$ \\
\hline \multicolumn{9}{|l|}{ Yaş } \\
\hline 44 yaş ve altı & $1,33 \pm 0,80$ & $0,57 \pm 0,94$ & $1,32 \pm 1,18$ & $1,32 \pm 0,57$ & $0,10 \pm 0,45$ & $1,65 \pm 0,89$ & $1,35 \pm 0,70$ & $7,70 \pm 2,97$ \\
\hline 45 yaş ve üzeri & $1,39 \pm 0,94$ & $0,71 \pm 1,00$ & $1,45 \pm 1,19$ & $1,37 \pm 0,58$ & $0,11 \pm 0,47$ & $1,62 \pm 0,94$ & $1,31 \pm 0,83$ & $7,94 \pm 3,25$ \\
\hline$p^{*}$ & 0,587 & 0,408 & 0,148 & 0,110 & 0,242 & 0,462 & 0,364 & 0,016 \\
\hline \multicolumn{9}{|l|}{ Eğitim Durumu } \\
\hline İlköğretim ve altı & $1,17 \pm 0,86$ & $0,64 \pm 0,98$ & $1,35 \pm 1,16$ & $1,25 \pm 0,52$ & $0,06 \pm 0,32$ & $1,41 \pm 0,90$ & $1,26 \pm 0,69$ & $7,14 \pm 3,14$ \\
\hline Ortaöğretim & $1,40 \pm 0,85$ & $0,63 \pm 1,00$ & $1,32 \pm 1,17$ & $1,37 \pm 0,58$ & $0,11 \pm 0,47$ & $1,58 \pm 0,92$ & $1,34 \pm 0,80$ & $7,79 \pm 3,26$ \\
\hline Yükseköğretim & $1,31 \pm 0,80$ & $0,60 \pm 0,98$ & $1,56 \pm 1,26$ & $1,36 \pm 0,63$ & $0,20 \pm 0,57$ & $1,58 \pm 1,01$ & $1,18 \pm 0,77$ & $7,54 \pm 2,93$ \\
\hline$p^{\star *}$ & 0,152 & 0,016 & 0,316 & 0,134 & 0,020 & 0,211 & 0,415 & 0,001 \\
\hline \multicolumn{9}{|l|}{ Hastalık Yılı } \\
\hline $1-5$ yıl & $1,40 \pm 0.85$ & $0,63 \pm 1,00$ & $1,32 \pm 1,17$ & $1,37 \pm 0,58$ & $0,11 \pm 0,47$ & $1,58 \pm 0,92$ & $1,34 \pm 0,80$ & $7,79 \pm 3,26$ \\
\hline 6-10 yıl & $1,31 \pm 0.80$ & $0,60 \pm 0,98$ & $1,56 \pm 1,26$ & $1,36 \pm 0,63$ & $0,20 \pm 0,57$ & $1,58 \pm 1,01$ & $1,18 \pm 0,77$ & $7,54 \pm 2,93$ \\
\hline 11 yıl ve üzeri & $1,92 \pm 0.95$ & $1,07 \pm 1,20$ & $1,92 \pm 1,07$ & $1,50 \pm 0,65$ & $0,14 \pm 0,36$ & $1,78 \pm 0,80$ & $1,57 \pm 0,93$ & $9,92 \pm 2,72$ \\
\hline$p^{\star *}$ & 0,001 & 0,662 & 0,134 & 0,000 & 0,037 & 0,324 & 0,076 & 0,002 \\
\hline \multicolumn{9}{|c|}{ Düzenli Egzersiz Yapma } \\
\hline Evet & $1,40 \pm 0,74$ & $1,48 \pm 0,76$ & $0,70 \pm 0,77$ & $0,14 \pm 0,45$ & $1,66 \pm 0,67$ & $0,07 \pm 0,26$ & $1,51 \pm 0,84$ & $6,96 \pm 3,12$ \\
\hline Hayır & $1,23 \pm 0,84$ & $0,95 \pm 0,92$ & $1,56 \pm 0,88$ & $1,37 \pm 0,56$ & $1,20 \pm 0,43$ & $0,00 \pm 0,00$ & $1,34 \pm 0,60$ & $7,65 \pm 3,80$ \\
\hline$p^{*}$ & 0,380 & 0,030 & 0,922 & 0,714 & 0,006 & 0,070 & 0,001 & 0,001 \\
\hline
\end{tabular}

$p<0,05 ; p<0,01 ; *$ Student $t$ testi, **0ne-Way ANOWA testi 


\section{TARTIŞMA}

AS hastalarında hem hastalığın kendisi hem de ortaya çıkan fiziksel problemler bu hastalarda uyku kalitesinin bozulmasına neden olabilmektedir $(4,8-10,13,18)$. Uyku bozukluğu, biliş, ruh hali ve hastalık semptomlarını ciddi şekilde bozarak hastaların yaşam kalitesini düşürebilmektedir (6). Bu nedenle AS hastalarında uyku bozukluklarının tespit edilmesi amaçlanmıştır.

Çalışmamızda AS hastalarının uyku kalitesinin kötü düzeyde olduğu ve uykusuzluk şiddetinin kontrol grubuna kıyasla AS grubunda daha yüksek olduğu görülmüştür. Yolbaş ve ark. (2017) yılında yaptıkları çalışmada AS hastalarında PUKi puanı $8,54 \pm 5,77$ olarak tespit edilmiştir. Ayrıca çalışmada uykuya dalmada gecikme, uyku kalitesinde azalma, uyku bozukluğu ve gündüz işlev bozukluğu gibi sorunların AS grubunda anlamlı olarak daha yüksek olduğu bildirilmiştir (14). AS hastalarında uyku bozukluğu prevalansının incelendiği bir başka çalışmada da AS hastalarında PUKI puanının 7,00 $\pm 4,21$ olduğu bildirilmiştir (15). Benzer şekilde Nie ve ark. (2018) yılında yaptıkları çalışmasında da AS hastalarında PUKi puanının 7,48 $\pm 3,84$ olduğu, hastaların $\% 67,6$ 'sının uyku kalitesinin kötü olduğu ve AS hastalarında uyku bozukluğu prevalansının normal popülasyondakilerden çok daha yüksek olduğu tespit edilmiştir (13). Çalışma sonucumuz bu yönü ile literatür ile benzerlik göstermektedir. Uyku bozukluğu insidansının AS hastalarında yüksek olması; başta ağrı olmak üzere, sabah tutukluğu, gecikmiş tanı süresi, ekstra spinal belirtiler, sınırlı gögüus genişlemesi ve kilo alımına bağlı olarak obstrüktif uyku apne sendromu, anksiyete, depresyon ve yorgunluk ile ilişkilendirilmektedir $(6,8,13)$. AS semptomları genellikle erken yetişkinlikte ortaya çıktığı için, uyku problemlerine bağlı gündüz disfonksiyonu, hastalar ve toplum için sosyoekonomik sonuçlar doğurabilir.

Çalışmamızda PUKi puanının yaş ile ilişkili olduğunu, yaşın ilerlemesi ile uyku kalitesinin düştüğü belirlenmiştir. Leverment ve ark. (2017) yılında yaptığı çalışmasında toplam PUKi ile artan yaşın birbirleriyle ilişkili olduğunu ve ileri yaşlardaki AS hastalarında uyku bozukluğu insidansının arttığını bildirmiştir (10). Shen ve ark. (2016) yılında sağlıklı kontroller ve AS hastaları ile yürüttükleri kohort çalışmasında, her iki grupta da uyku bozukluğu insidansının yaş ile birlikte arttığını ancak AS hastalarının, tüm yaş gruplarında AS olmayan kohorttan daha fazla uyku bozukluğu gelişme insidansına sahip olduğunu bildirmişlerdir (6). Jiang ve ark. (2018) yılında yaptıkları çalışmada da AS hastalarında artan yaşın uyku bozukluğu ile ilişkili olduğunu tespit etmişlerdir (15). Çalışma sonuçlarına göre ileri yaşlardaki AS hastalarında uyku bozukluğu artacağı için dikkat edilmesi gerektiği sonucuna varılmıştır. Ek olarak, uyku düzeninin yaşam boyunca doğal olarak değişebileceği, ileri yaşlarda uyku intiyacının da azalabileceği göz önünde bulundurulmalıdır (6).

Çalışmamızda uyku kalitesinin eğitim durumu ve hastalık yılı ile ilişkili olduğu belirlenmiştir. Jiang ve ark. (2018) çalışmasında uyku bozukluğu ile hastalık süresi arasında pozitif, eğitim durumu ile negatif bir ilişki olduğu saptanmıştır (15). AS hastalarını dahil eden bir sistematik derlemede de uyku bozukluğunun eğitimde geçirilen yıl ile ters ilişkili olduğu ancak hastalık yılı ile pozitif ilişkili olduğu belirtilmiştir (10). Benzer şekilde Abdulaziez ve Asaad (2012) uyku kalitesinin hastalık süresi ile ilişkili olduğunu, Li ve ark. (2012) ise eğitim seviyesi ile ilişkili olduğunu bildirmişlerdir $(19,20)$. In ve ark. (2015) ile Aydın ve ark. (2015) çalışmalarında ise bu çalışma sonuçlarından farklı olarak hastalık süresi ile uyku bozukluğu arasında bir ilişki olmadığı, uyku verimliliğinin hastalık süresi ile değil ciddiyeti ile ilişkili olduğu vurgulanmıştır $(12,21)$. Çalışma sonucumuz bu yönü ile genel literatür ile benzerlik göstermektedir.

Uyku kalitesindeki düşüşün sebeplerinden biri de fiziksel aktivitenin azalması olarak ifade edilmektedir $(7,8,13,22)$. Çalışmamızda AS hastalarında egzersiz ile uyku kalitesinin ilişkili olduğu görülmüştür. Ürkmez ve Keskin (2020) yılında yapmış oldukları çalışmada; hasta grubunun fiziksel aktivite düzeyinin sağlıklı katılımcılara göre daha düşük olduğu ve fiziksel aktivite düzeyi düşük olan AS hastalarında PUKİ uyku bozukluğu bileşenlerinin anlamlı olarak daha yüksek olduğu bulunmuştur (8). Masiero ve ark. (2011) çalışmasında, bir eğitim-davranış programı ve anti-TNF tedavisi ile birlikte egzersizin, AS hastalarında hastalık aktivitesinin semptomları üzerinde, tek başına kullanılan müdahalelerden daha büyük bir etkiye sahip olduğunu bulmuşlardır (23). Egzersiz, omurga hareketliliğini sürdürmek, ağrıyı azaltmak ve zihinsel sağlığı desteklemek için AS hastalarında semptom yönetmede yaygın olarak kullanılmaktadır (7). Bu nedenle AS hastaları için non-farmakolojik tedavi olarak egzersiz miktarını ve düzeyini planlamak da önemlidir (24). Çünkü düşük fiziksel aktivite, yüksek hastalık aktivitesine, düşük uyku kalitesine ve diğer sorunlara yol açabilmektedir $(8,13,22,24)$. Bu nedenle, AS hastalarında uyku kalitesini iyileştirmek için tedavinin bir parçası olarak rutin olarak egzersiz yapmaları önerilebilir ancak egzersizin uyku kalitesini iyileştirme üzerindeki etkilerini açıklığa kavuşturmak için daha fazla araştırmanın yapılması gerektiği düşünülmektedir.

\section{SONUÇ}

AS'li hastaların sağlıklı bireylere kıyasla kötü uyku kalitesine sahip olduğu ve yaş, eğitim durumu, hastalık yılı ve egzersiz yapma durumlarının uyku kalitesini etkilediği saptanmıştır. Uyku bozuklukları, AS hastalarında psikiyatrik sorunlara, bozulmuş bilişsel işlevselliğe, yorgunluğa ve artmış yaralanma riskine neden olarak hastaların yaşam kalitesini olumsuz etkileyebilmektedir. Uyku bozukluklarının sağlık üzerindeki bu olumsuz etkileri de önemli ekonomik kayıplara yol açabilmektedir. Bu nedenle sağlık personeli tarafından AS'li hastalarda uyku problemlerine neden olan durumların tespit edilmesi ve bu durumlara ilişkin gerekli girişimlerin yapılması önerilmektedir. Ayrıca AS'li hastalara sigara bıraktırma eğitimlerinin verilmesi, düzenli kontrollere gelmenin ve 
egzersizin önemi hakkında bilgilendirme yapılmalıdır.

Finansal destek: Çalışmayı maddi olarak destekleyen kişi/kuruluş yoktur.

Çıkar Çatışması: Yazarlar arasında herhangi bir çıkar çatışması yoktur.

Etik onay: Çalışma için Burdur Mehmet Akif Ersoy Üniversitesi Girişimsel Olmayan Klinik Araştırmalar Etik Kurulu'ndan etik kurul izni (Karar No: GO 2018/37) ve çalışmanın yürütüldügüü kurumun Romatoloji $A D$ başkanından da izin alındı.

\section{REFERENCES}

1. Duruoz MT, Ulutatar F, Ozturk EC, et al. Assessment of the validity and reliability of the Jenkins Sleep Scale in ankylosing spondylitis. Int J Rheum Dis 2019;22-:275-9.

2. Öksüz S, Ünal E, Er G, et al. Kuzey Kıbrıs Türk Cumhuriyeti'nde yaşayan ankilozan spondilitli hastaların biyopsikososyal özellikleri arasındaki ilişkinin incelenmesi: pilot çalışma. J Exerc Ther Rehabil 2017;4:9-17.

3. Yüksel GA. Sleep quality and restless legs syndrome in patients with ankylosing spondylitis. Haydarpasa Numune Train Res Hosp Med J 2018;59:78-83.

4. Mease $P$, Walsh JA, Baraliakos $X$, et al. Translating improvements with ixekizumab in clinical trial outcomes into clinical practice: ASAS40, pain, fatigue, and sleep in ankylosing spondylitis. Rheumatol Ther 2019;6:435-50.

5. Ölmeztürk ÖÖ, Doğru A, Şahin M. Ankilozan spondilitli erkek hastalarda cinsel disfonksiyonun değerlendirilmesi. SDÜ Sağlık Bilimleri Enstitüsü Dergisi 2018;9:19-25.

6. Shen T-C, Liang S-J, Lin C-L, et al. Ankylosing spondylitis and the subsequent risk of sleep disorders: a retrospective population based cohort study in Taiwan. J Intern Med 2016;27:79-88.

7. Tyrrell JS, Redshaw $\mathrm{CH}$. Physical activity in ankylosing spondylitis: evaluation and analysis of an eHealth tool. J Innov Health Inform 2016;23:169.

8. Urkmez B, Keskin Y. Relationship between sleep quality and physical activity level in patients with ankylosing spondylitis. Mod Rheumatol 2020;30:1053-59.

9. Leverment S, Clarke E, Wadeley A, et al. Prevalence and factors associated with disturbed sleep in patients with ankylosing spondylitis and non-radiographic axial spondyloarthritis: a systematic review. Rheumatol Int 2017;37:257-2571.

10. Li Z, Fu T, Wang Y, et al. Sleep disturbances in ankylosing spondylitis: a systematic review and meta-analysis. Psychol Health Med 2019;24:911-24.
11. Altunalan A, Buğdaycı D, Paker N, et al. Ankilozan spondilitli hastalarda uyku bozukluğunun hastalık aktivitesi ve yaşam kalitesiyle ilişkisi. İstanbul Fiz Tıp Rehabil Derg 2016;21-6.

12. İn E, Turgut T, Gülkesen A, et al. Obstructive sleep apnea syndrome and sleep efficiency in patients with ankylosing spondylitis. Arch Rheumatol 2015;30:326-33.

13. Nie A, Wang $C$, Song $Y$, et al. Prevalence and factors associated with disturbed sleep in outpatients with ankylosing spondylitis. Clin Rheumatol 2018;37:2161-8.

14. Yolbaş S, Yıldırım A, Düzenci D, et al. Sleep quality, sleeping postures, and sleeping equipment in patients with ankylosing spondylitis. Turk J Med Sci 2017;1198-205.

15. Jiang $Y$, Yang $M, L v Q$, et al. Prevalence of psychological disorders, sleep disturbance and stressful life events and their relationships with disease parameters in Chinese patients with ankylosing spondylitis. Clin Rheumatol 2018;37:407-14.

16. Buysse DJ, Reynolds CF, Monk TH. The Pittsburgh sleep quality index: a new instrument for psychiatric practice and research. Psychiatry Res 1989;28:193-213.

17. Ağargün $M Y$, Kara $H$, Anlar $O$. Pittsburgh uyku kalitesi indeksinin geçerlik ve güvenirliği. Türk Psikiyatri Derg. 1996;7:107-15.

18. Durmus D, Sarısoy G, Alaylı G, et al. Psychiatric symptoms in ankylosing spondylitis: their relationship with disease activity, functional capacity, pain and fatigue. Compr Psychiatry 2015;62:170-77.

19. Abdulaziez O, Asaad T. Sleep problems in ankylosing spondylitis: polysomnographic pattern and disease related variables. Egypt Rheumatol 2012;34:59-65.

20. Li Y, Zhang S, Zhu J, et al. Sleep disturbances are associated with increased pain, disease activity, depression, and anxiety in ankylosing spondylitis: a case-control study. Arthritis Res Ther 2012;14:R215.

21. Aydin E, Bayraktar K, Turan Y, et al. Sleep quality in patients with ankylosing spondylitis. Rev Bras Reumatol 2015;55:340-5.

22. Deodhar A, Gensler LS, Magrey M, et al. Assessing physical activity and sleep in axial spondyloarthritis: measuring the gap. Rheumatol Ther 2019;6:487-501.

23. Masiero S, Bonaldo L, Pigatto $M$, et al. Rehabilitation treatment in patients with ankylosing spondylitis stabilized with tumor necrosis factor inhibitor therapy. a randomized controlled trial. J Rheumatol 2011;38:1335-42.

24. Millner JR, Barron JS, Beinke KM, et al. Exercise for ankylosing spondylitis: an evidence-based consensus statement. Semin Arthritis Rheum 2016;45:411-27. 